\title{
Environmental Monitoring and Potential Health Risk Assessment from Pymetrozine Exposure among Communities in Typical Rice-Growing Areas of China
}

\section{Muyesaier Tudi}

Griffith University School of Medicine

Huada Daniel RUAN

Griffith University

\section{Shuangmei Tong}

Chinese Academy of Sciences

li wang ( $\nabla$ wangli@igsnrr.ac.cn )

Institute of Geographical Sciences and Natural Resources Research, Chinese Academy of Sciences

Albert Atabila

Griffith University

Ross Sadler

Griffith University

Des Connell

Griffith University

Dung Tri Phung

Griffith University

\section{Research Article}

Keywords: agriculture communities, China, environmental routes, health risk, Pymetrozine

Posted Date: July 12th, 2021

DOI: https://doi.org/10.21203/rs.3.rs-618003/v1

License: (c) (i) This work is licensed under a Creative Commons Attribution 4.0 International License. Read Full License

Version of Record: A version of this preprint was published at Environmental Science and Pollution Research on April 7th, 2022. See the published version at https://doi.org/10.1007/s11356-022-19927-z. 



\section{China}

4 Muyesaier.Tudi ${ }^{1,2}{ }^{1}$ Huada Daniel RUAN ${ }^{3,4}$, Shuangmei Tong ${ }^{1,6}{ }^{1}$ Li Wang ${ }^{1,5,6 *}$, Albert Atabila ${ }^{7}$, Ross

$5 \quad$ Sadler $^{2}$, Des Connell ${ }^{3}$, Dung Tri Phung ${ }^{2}$

6

71 Key Laboratory of Land Surface Pattern and Simulation, Institute of Geographical Sciences and

8 Natural Resources Research, Chinese Academy of Sciences, No. 11 Datun Road, Beijing, 100101,

9 China

102 Centre for Environment and Population Health, School of Medicine, Griffith University, 170 Kessels

11 Road, Nathan QLD 4111, Australia

123 School of Environment and Science, Griffith University, 170 Kessels Road, Nathan QLD 4111,

13 Australia

144 Beijing Normal University-Hong Kong Baptist University United International College, 2000 Jintong

15 Road, Tangjiawan, Zhuhai, Guangdong Province, China

165 Faculty of Health, Medicine and Life Sciences, Maastricht University, 6200, MD Maastricht, the

17 Netherlands

186 College of Resources and Environment, University of Chinese Academy of Sciences, Beijing 100049,

19 China.

207 Department of Biological, Environmental \& Occupational Health Sciences, School of Public Health,

21 University of Ghana, P. O. Box LG13, Legon, Accra, Ghana

22

Li Wang

24

Email: wangli@igsnrr.ac.cn

25 
Abstract:

Pymetrozine is one of the most common insecticides used in China. This study was conducted to analyse Pymetrozine's potential exposures through various environmental routes beyond the treatment area. The aim was to estimate the potential health risk for communities due to non-dietary exposure to Pymetrozine in soil and paddy water. Data on registration of pesticides in China, government reports, questionnaires, interviews, literature reviews as well as toxicological health investigations were evaluated to determine the hazard and dose-response characteristics of Pymetrozine. These were based on the US EPA exposure and human health risk assessment methods using exposure from soil and paddy water samples collected between 10 to 20 meters around the resident's location. The potential exposures from dermal contact through soil and paddy water were estimated. The potential cancer risk from the following routes was evaluated: the ingestion through soil; dermal contact exposure through soil; dermal contact exposure through paddy water; and the potential total cancer risk for residents was less than $1 * 10^{-6}$. These were within the acceptable risk levels. The potential hazard quotient (HQ) from acute and lifetime exposure by dermal contact through paddy water and soil; acute and lifetime exposure by soil ingestion for residents were less than 1 , indicating an acceptable risk level, thus both potential cancer risk and hazard quotient (HQ) were relatively low. Potential human health risk assessment of Pymetrozine in soil and paddy water suggested that negligible cancer risk and non-cancer risk based on ingestion and dermal contact are the main potential routes of exposure to residents. 


\section{Introduction}

60 Pesticides play a significant role in reducing the losses of agricultural products and improve the affordable yield and quality of food (Aktar et al., 2009, Schreinemachers et al., 2017). Pesticides can be toxic to other organisms, including birds, fish, beneficial insects, and nontarget plants, as well as contaminate air, water, soil, and crops (Tudi et al., 2021). Moreover, pesticide contamination can move away from the application areas resulting in environmental pollution. Such chemical residues impact human health through environmental and food contamination (Yadav et al., 2015).

67

Although some measures have been proposed to reduce the negative effects of pesticides on the environment and human health (Phung et al., 2012c), both acute and chronic human toxicities resulting from these substances remain a serious problem (Tudi et al., 2021). It is predicted that the high-risk of pesticide exposure will increase worldwide over the next decade, especially in developing countries (Delcour et al., 2015). China leads the world in both pesticide production and consumption (Zhang et al., 2011). There was an increase in the use of pesticides from 1.28 million tons in 2000 to 1.8 million tons in 2013 , with an average annual increase of 2.7\% reported for 2018 (Shuqin and Fang, 2018).

It has been reported that $70 \%$ of the pesticides used in China were not absorbed by plants and other organisms, instead they have entered into the soil and groundwater (Wang et al., 2018). Thus, many non-farmworker residents living close to agricultural lands where pesticides are often used intensively are exposed to pesticides. Owing to the intrinsic toxicity of pesticides, it is important to evaluate the potential health consequences for this specific population, but such evaluations are largely absent in studies to date. 
Pymetrozine $\{4$, 5-dihydro-6-methyl-4-[(3-pyridylmethylene)-amino]-1, 2, 4-triazine-3(2H)-

one \} which has the basic structure of a pyridine azomethine (Zhang et al., 2015). Currently, is widely used in China (Jia et al., 2019, Gong et al., 2019, Kovacova et al., 2013). In addition, Pymetrozine has recently replaced organic phosphate pesticides although organophosphate pesticides continue to be used in some other countries in the world (Hamsan et al., 2017,Atabila et al., 2018, Phung et al., 2012a ). But little is known of the potential risk posed to residents on adjoining land, from using Pymetrozine. A first step in the development of a potential health risk assessment in respect to this chemical must be to gain an understanding of its environmental distribution, attenuation, and fate under field conditions.

Pymetrozine has a negative influence on reproduction, causes irritation to the respiratory tract (European Food Safety, 2017) Furthermore, Pymetrozine has brought great benefits to crop production by killing insects. The United States Environmental Protection Agency (USEPA) classifies Pymetrozine as a possible human carcinogen and a cancer slope factor of is 0.0019 $\mathrm{mg} / \mathrm{kg}$ quoted by USEPA (2010), and this will be further considered in the present evaluation. However, most previous studies of these parameters were not carried out under field conditions (Europe Food safety Authority, 2014).

This study was conducted to analyse Pymetrozine potential exposures through the environmental routes for residents living close to agricultural lands in typical rice growing areas of China, to estimate potential health risk for residents due to non-dietary exposure to Pymetrozine in soil and paddy water. This study will provide scientific information for policy makers to set the proper pesticide application techniques and methods to minimize the pesticide exposure relating to health effects for communities. 


\section{Study Area}

110

The study area was identified with the assistance of the Institute of Plant Protection Chinese Academy of Agricultural Science and Beijing ECO-SAF Technology Co., Ltd. Based on the location of the Institute of Plant Protection Chinese Academy of Agricultural Science and Beijing ECO-SAF Technology Co., Ltd and local government, the typical rice-growing areas of Hunan and Guangxi provinces were selected as the study areas.

In the present study, the Yun-Wen Village Shang Lin Country Nan Ning City Guangxi Province and Hua Tang Village Chang Sha Country Chang Sha City Hunan Province were the study areas (Figure 1). Samples of paddy soil and paddy water were collected in association with a spraying event. Farmers sprayed pesticides once a month. Residents lived within 10-20 meters of their agriculture areas.

\section{Martials and Methods}

\section{$123 \quad 3.1$ Sample Collection}

124 The quartering sampling method ( $\mathrm{Li}, 2008)$ was used to collect soil and paddy water samples. Four samples were collected from the surface (0-15 cm layer) in every plot (size about 2000 $\mathrm{m}^{2}$ ), composited and stored in a polyethylene bag as one sample. Fifteen soil and fifteen paddy water samples were collected in each region. Samples were collected on the day prior to spraying, the day of spraying insecticides and 1, 3, 5, 7, 9, 14, 21 and 28-days after insecticide spraying. All the samples were stored at $-20^{\circ} \mathrm{C}$ immediately prior to analysis and the samples were analysed within the one month. 
133 Based on the previous study (Li et al., 2011), the modified QuEChERS method was adapted to analyse both of the soil and paddy water samples. The parameters including linearity, linear range, LOQs, accuracy, precision and stability were considered to evaluate the method validation. The result indicated that the analytical method of Pymetrozine was accuracy and precision and it meets the requirement.

\subsection{Exposure Assessment through Environmental Media}

Pymetrozine has only recently replaced organophosphate insecticides, thus there are very few studies regarding the exposure of operators and the community. Ingestion of vegetables and fruits is considered as the main exposure route of Pymetrozine in previous studies conducted in China (Jia et al., 2019, Gong et al., 2019, Kovacova et al., 2013, Yu et al., 2020). However, there is little study focus on the Pymetrozine exposure from soil and paddy water and its environmental health risk assessment for the agriculture communities in China.

In this study, the soil and paddy water samples collected within 10-20 meters of the residents' apartments and two main potential pathways of the exposure assessment were considered. Dermal contact and ingestion are the main exposure routes of communities exposed to Pymetrozine in soil and paddy water in the study areas.

Developing a conceptual site model (CSM) can assist the process of understanding how human 'receptors' may be exposed to chemicals from relevant environmental sources. The CSM describes the sources of contamination, the pathways by which contaminants may migrate through the various environmental media and the populations that may potentially be exposed. CSMs are particularly important in environmental health risk assessment of contaminated sites and based on these aspects, the conceptual framework was settled in this study (Figure 2). 
3.3.1 Calculation of Absorbed Daily Dose (ADD) of Pymetrozine from Dermal Exposure

The Absorbed Daily Dose (ADD) of Pymetrozine from dermal exposure in one spraying event was estimated using the following equation:

$$
\text { ADD dermal }=\frac{C * S A * S L * A B S}{B W} * 10^{-6}
$$

Where, ADD is the average daily dose via dermal contact;. $C$ is the concentration of pymetrozine in soil or water sample $(\mu \mathrm{g} / \mathrm{kg}) ; B W$ is body weight $(\mathrm{kg}) ; S A$ is the exposed skin area $\left(\mathrm{m}^{2}\right)$, reported by the Environmental Ministry of China (2010); SL is the skin adherence factor; and $A B S$ is the dermal absorption factor for pymetrozine (US EPA, 2000) (TableS1).

\subsubsection{Calculation of Absorbed Daily Dose (ADD ingestion) Pymetrozine from Ingestion}

\section{Exposure}

ADD of pymetrozine from ingestion exposure in one spraying event was estimated using the following equation:

Where, ADD ingestion is the average daily doses of via ingestion; $C$ is the concentration of pymetrozine in soil sample $(\mu \mathrm{g} / \mathrm{kg})$; IngR is the ingestion rate for pymetrozine (US EPA, 2000); and $B W$ is body weight (Environmental Ministry of China, 2010) (Table S1). 
181

182

183

184

In this section, based on the results of the acute ingestion exposure level of Pymetrozine from soil (on the day insecticide spraying,1,3,5,7,9,14, and 21-day after insecticide spraying in one spraying event separately), the acute dermal exposure level of Pymetrozine from soil (on the day of insecticide spraying, 1,3,5,7,9,14, and 21-day after insecticide spraying in one spraying event separately) and the acute dermal exposure level of Pymetrozine from paddy water (on the day insecticide spraying,1,3,5,7,9 and 14-day after insecticide spraying in one spraying event separately) were calculated, and then sum of the post-application exposure dose to calculate the total acute dermal exposure level of Pymetrozine from soil, the total acute dermal exposure level of Pymetrozine from paddy water; and the total acute ingestion exposure level of Pymetrozine from soil separately.

\subsubsection{Calculation of Lifetime Average Daily Dose (LADD) of Pymetrozine from Dermal and Ingestion Exposure}

The Lifetime Average Daily Doses (LADD) of Pymetrozine from dermal exposure and ingestion by the communities were estimated using the following equations:

$$
\text { LADD dermal }=(\operatorname{ADD}(\text { dermal }) \times E F \times E D) / A T
$$

Where, $\mathrm{ADD}(\mathrm{mg} / \mathrm{kg} / \mathrm{day})$ is the sum of dermal absorbed daily dose and the ingestion absorbed daily dose of Pymetrozine of the communities; LADD is the lifetime average daily dose of Pymetrozine; EF is the exposure frequency (number of days per year); there are four spraying times in this study area and the concentration level of the Pymetrozine in soil was detected 
205

206

207

208

209

210

211

212

213

214

215

216

217

218

219

220

221

222

223

224

225

226

227

from the day insecticide spraying until after 21-day insecticide spraying; and the concentration level of Pymetrozine in paddy water was detected from the day insecticide spraying until after 14-day insecticide spraying, thus the frequencies of exposure for soil and paddy water were 84 days and 56days separately. ED is the exposure duration (lifetime years) and the exposure duration for adults is 70 years. AT is the life expectancy in years and the life expectancy for adults is $\left(365^{*} 70\right)$. (Table $\left.\mathrm{S} 1\right)$.

\subsection{Potential Environmental Health Risk Characterization}

The potential health risks caused by main routes of exposure to chemical contaminants in environment were assessed based on the health risks models of the U.S. EPA (2004).

\subsubsection{Non-carcinogenic hazard quotient (HQ)}

The non-cancer risks of exposure to Pymetrozine in soil and paddy water were calculated as follows (Eqs. (5)- (6):

$$
\mathrm{HQ}=\frac{l A D D}{R F D}
$$

$$
\mathrm{HI}=\sum H Q
$$

\section{As stated earlier, Acute and Lifetime Average Daily Dose (LADD) of Pymetrozine in soils and} paddy water through multiple pathways were calculated using Eqs. (1)- (4) Separately. The hazard quotient (HQ) represents the non-carcinogenic risk for Pymetrozine through different exposure pathways. The reference doses $(R F D)$ were taken from the U. S. Department of Energy's RAIS compilation (U. S. Department of Energy 2000 and 2010). The hazard index 
228

229

230

231

232

233

234

235

236

237 238

239

240

241

242

243

244

245

246

247

248

249

250

251

(HI) represents the total non-carcinogenic risk for Pymetrozine through different exposure pathways.

\subsubsection{Carcinogenic risk}

The carcinogenic risk (CR) is the incremental probability of an individual developing cancer over a lifetime due to carcinogenic exposure. The carcinogenic risk is evaluated by Eq. (7):

$$
C R=L A D D \times C S F
$$

The estimated $C R$ is the probability of an individual developing in any type of cancer from lifetime exposure to carcinogenic hazards. (LADD) is the lifetime average daily dose of Pymetrozine and CSF is the cancer slope factor, and it is expressed in $(\mu \mathrm{g} / \mathrm{kg} / \mathrm{day})^{-1}$.

To evaluate the total potential cancer risks (TCR) from different pathways for soil and paddy water, these parameters were calculated using Eq. (8).

$$
T C R=\sum^{n} \mathrm{CR}
$$

$C R$ is the individual carcinogenic risk of every pathway; $n$ is different pathways that cause cancer risk.

\section{Results and Discussion}

\subsection{Hazard Identification of Pymetrozine}

The identification of Pymetrozine as the major hazard to community's health was carried out by using data on registration of pesticide in China, government report, questionnaire and interview, and literature reviews as well as toxicological health investigation.

\subsubsection{Pymetrozine Formulations Used in China}


In China, since 2008, because Pymetrozine is being employed as a main substitute for pesticides of high toxicity, there exists a need to properly quantitate the human health risks that result from the used of Pymetrozine in rice paddies (Wu, et al, 2013; Jiang Su government report, 2017).

\subsubsection{Human Health Effects of Pymetrozine Usage in China}

Residents are exposed to the residue of pesticides through environmental media such as soil, water and food by different routes of exposure including inhalation, ingestion and dermal contact; and that lead to acute and chronic diseases (Damalas and Eleftherohorinos, 2011).

From the survey and interview in our study (Table S2), it could be found that most of the farmers use the locally made spraying equipment which doesn't have appropriate safeguards. As a result of substandard construction of the equipment, cracks and leaks can happen easily during the application. In addition, applicators have either inadequate or no protective clothing, masks, and gloves. Furthermore, owing to the lack of proper instruction and training farmers do not identify the harmful pests from the other non-harmful pests and use the incorrect nozzles. The spraying equipment which farmers use is not properly cleaned and handled when they finish the spraying. Therefore, owing to the spills and splashes, direct spray contact, or even drift during the pesticide application under the improper way, agriculture workers and residents living around the agriculture land are potentially exposed to pesticides via dermal contact, ingestion and respiratory inhalation (Sugeng et al., 2013).

It was observed that there are many discarded pesticide packaging bags in the study areas. After pesticides are used to target plants, they will go through transfer/migration and degradation in the environment (Tudi et al., 2021). Improper use of pesticide, its management and behavior 
also lead to environmental pollution (Connell, 2018) including soil, water, air, and food contamination. The residues of pesticides from these different environmental medias may enter the human body and result in negative impact on human health (Tudi et al., 2021).

Currently, there are very few studies related to the health effects of Pymetrozine in China and other countries. Previous studies indicate that acute toxic effects always occur from within a few minutes to several hours after poisoning by pesticides (Yang and Deng, 2007, DeBleecker, 1995, Pereira et al., 2015, Atabila et al., 2018b). Also, the documented issues indicate that various chronic diseases and disorders sometimes occur after people have been exposed to pesticides (Wesseling et al., 1997, Uram, 1989, Phung et al., 2012b). Therefore, there may be exposure and potential health effects from Pymetrozine application by the occupational, environmental and dietary routes to both agriculture workers and residents who are living around the agriculture areas.

\subsection{Potential Exposure Assessment of Pymetrozine through Environmental Media}

\subsubsection{Baseline Exposure Levels of Pymetrozine through Environment with Agriculture}

\section{Communities}

Soil and paddy water were collected one-day prior to application, and the concentration level of Pymetrozine in soil and paddy water were analysed. The Pymetrozine concentration level in soil and paddy water which were collected one-day prior to application is under the detection, thus the baseline exposure level of Pymetrozine in the environment was set to be zero.

4.2.2 Potential Acute Dermal and Ingestion Exposure Levels of Pymetrozine in Communities 
Based on the concentration level of Pymetrozine in soil and paddy water and the US EPA (2004) exposure assessment method, the potential acute dermal exposure level of Pymetrozine in soil and paddy water and the potential acute ingestion exposure level of Pymetrozine in soil were calculated for each day of each sampling site during one spraying event (day of insecticide spraying, 1-day after insecticide spraying, 3-day after insecticide spraying, 5-day after insecticide spraying, 7-day after insecticide spraying, 9-day after insecticide spraying, 14-day after insecticide spraying and 21-day after insecticide spraying).

The concentration level of Pymetrozine on the day of insecticide spraying varies in different agriculture lands. The application rate by different farmers, the target areas of the sprayed insecticide and the kind of equipment used by different farmers are different, and these are the main reasons caused the differences in the initial concentration level of Pymetrozine in the soil and the exposure level of Pymetrozine through the soil ( $\mathrm{Li}, 2010)$. In addition, the previous study also shows that the initial concentration level of Pymetrozine is related to the difference in sampling strategy, the difference in climate and soil characteristic, the density of rice planting and the difference in growth trends (Yang, 2011). These are further main reasons for the difference in Pymetrozine acute dermal exposure level and acute ingestion exposure level through soil in different agriculture lands in both Hunan and Guangxi areas.

The potential minimum, mean, $95^{\text {th }}$ percentile, and maximum values of the potential acute dermal exposure through soil and paddy water, and potential acute ingestion exposure through soil for adults in Guangxi and Hunan after Pymetrozine application are plotted in TableS3, S4 and S5, separately. The result indicates that adults were exposed to Pymetrozine from the day of insecticide spraying until 21 days after insecticide spraying. The potential acute dermal exposure through soil was higher than acute dermal exposure through paddy water in both 
326 Guangxi and Hunan areas. The potential acute dermal exposure level through soil; the potential

327 acute dermal exposure level through paddy water were lower than the potential acute ingestion exposure level through soil for adults in both areas separately.

Table S3 indicate that the potential acute dermal exposure level for adults through soil in Hunan on the day of Pymetrozine application was increased to $1.2 \mathrm{E}^{*} 10^{-6} \mu \mathrm{g} / \mathrm{kg} / \mathrm{day}$ which was 1.2 $\mathrm{E}^{*} 10^{-6}$-fold higher than the baseline exposure level. The potential exposure level decreased to $0.02 \mathrm{E}^{*} 10^{-6} \mu \mathrm{g} / \mathrm{kg} / \mathrm{day}$ after 21 days of insecticide spraying. The potential acute dermal exposure level for adults through soil in Guangxi on the day of Pymetrozine application increased to $1.1 \mathrm{E}^{*} 10^{-6} \mu \mathrm{g} / \mathrm{kg} /$ day which was $1.1 \mathrm{E}^{*} 10^{-6}$-fold higher than the baseline exposure level. The potential exposure level decreased to $0.02 \mathrm{E}^{*} 10^{-6} \mu \mathrm{g} / \mathrm{kg} / \mathrm{day}$ after 21 -days of insecticide spraying.

Table S4 indicate that the potential acute dermal exposure level for adults through paddy water in Hunan on the day of Pymetrozine application increased to $0.5 \mathrm{E}^{*} 10^{-6} \mu \mathrm{g} / \mathrm{kg} / \mathrm{day}$ which was $0.5 \mathrm{E}^{*} 10^{-6}$-fold higher than the baseline exposure level. The potential exposure level decreased to $0.04 \mathrm{E}^{*} 10^{-6} \mu \mathrm{g} / \mathrm{kg} /$ day after 14 days of insecticide spraying. The potential acute dermal exposure level for adults through paddy water in Guangxi on the day of Pymetrozine application increased to $0.6 \mathrm{E}^{*} 10^{-6} \mu \mathrm{g} / \mathrm{kg} /$ day which was $0.6 \mathrm{E}^{*} 10^{-6}$-fold higher than the baseline exposure level. The potential exposure level decreased to $0.04 \mathrm{E}^{*} 10^{-6} \mu \mathrm{g} / \mathrm{kg} / \mathrm{day}$ after 14 days of insecticide spraying.

Table S5 indicate that the acute ingestion exposure level for adults through soil in Hunan on the day of Pymetrozine application increased to $1.02 \mathrm{E}^{*} 10^{-4} \mu \mathrm{g} / \mathrm{kg} / \mathrm{day}$ which was $1.02 \mathrm{E}^{*} 10^{-4}$ -fold higher than the baseline exposure level. The potential exposure level decreased to 1.73 $\mathrm{E}^{*} 10^{-6} \mu \mathrm{g} / \mathrm{kg} /$ day after 21 days of insecticide spraying. The potential exposure level decreased 
to $4.18 \mathrm{E}^{*} 10^{-6} \mu \mathrm{g} / \mathrm{kg} / \mathrm{day}$ after 21 days of insecticide spraying. The potential acute ingestion exposure level for adults through soil in Guangxi on the day of Pymetrozine application increased to $7.64 \mathrm{E}^{*} 10^{-5} \mu \mathrm{g} / \mathrm{kg} / \mathrm{day}$ which was $7.64 \mathrm{E}^{*} 10^{-5}$-fold higher than the baseline exposure level. The potential exposure level decreased to $5.439 \mathrm{E}^{*} 10^{-5} \mu \mathrm{g} / \mathrm{kg} / \mathrm{day}$ after $14 \mathrm{days}$ of insecticide spraying.

\subsubsection{Potential Total Acute Exposure of Pymetrozine in Communities}

The descriptive analysis was carried out on the total acute dermal exposure level of Pymetrozine through soil, the total acute ingestion exposure level of Pymetrozine through soil, the total acute dermal exposure level of Pymetrozine through paddy water in Guangxi and Hunan. The results are shown in Table S6. It shows that there is no significant difference between the total dermal exposure from soil ( on the day insecticide spraying, 1, 3,5,7, 9,14 and 21-day after insecticide spraying) and the acute soil dermal exposure on the day insecticide spraying; there is no significant difference between the total dermal exposure from paddy water and the acute dermal exposure from paddy water on the day insecticide spraying; and there is no significant difference between the total ingestion exposure level from soil and the acute ingestion exposure level from soil on the day insecticide spraying for adults in Guangxi and Hunan.

\subsubsection{Potential Lifetime Average Daily Dose (LADD)}

Based on the potential total acute dermal exposure levels of Pymetrozine through soil; potential total acute ingestion exposure levels of Pymetrozine through soil; and the potential total acute dermal exposure levels of Pymetrozine through paddy water during the one spraying event, the potential life-time exposure levels of Pymetrozine in soil and paddy water were calculated for each sampling point. The results of the descriptive analysis are indicated in Table S7. The 
378 LADD for Pymetrozine exposure with agriculture communities assumed that the farmers

379 sprayed the same amount of Pymetrozine for every spray event and communities are exposure to Pymetrozine in short-time period in every year.

\subsection{Potential Environmental Risk Characterization of Pymetrozine exposure for agriculture communities}

The potential cancer risk assessment of Pymetrozine through dermal contact, and ingestion exposure routes for adults, as well as the exposure doses of Pymetrozine in relation to adults' potential non-carcinogenic risk through dermal contact and ingestion exposure routes in Hunan and Guangxi were calculated using the parameters of the US EPA health risk assessment method in this study.

Since there are no human studies about the Pymetrozine, to make summaries derived from the results of sub-chronic and chronic toxicity, metabolism, and dermal penetration studies in animals, these studies indicate that Pymetrozine impacts on three major organs in the body including liver, hematopoietic system, and lymphatic system. In addition, from both subchronic and chronic studies from dogs, it is found that this chemical affects muscle tissue. Pymetrozine has been reported that it has significant adverse health effects on mice, rats, and dogs (US EPA, 2000). For example, hepatocellular hypertrophy is related to induction of drug metabolizing enzymes (USEPA, 2010). The EPA also classifies Pymetrozine as a possible human carcinogen (USEPA, 2010).

According to the available slope factors discussed by the US EPA (2010), dermal contact and ingestion were involved in the risk estimation of Pymetrozine. The cancer slop factor is 0.0019 $\mathrm{mg} / \mathrm{kg}$. The value of the Chronic Population-Adjusted Dose from Pymetrozine for general 
403

404

405

406

407

408

409

410

411

412

413

414

415

416

417

418

419

420

421

422

423

424

425

426

427

population is $0.0038 \mathrm{mg} / \mathrm{kg} /$ day that was used to calculate the non-cancer risk for lifetime exposure dose. The value of the Acute Population-Adjusted Dose from Pymetrozine for general population is $0.42 \mathrm{mg} / \mathrm{kg}$ and that was used to calculate the non-cancer risk for acute exposure dose.

\subsubsection{Potential Cancer Risk}

The distribution of potential cancer risk is presented in Figure 3 and Table S8. The potential cancer risk of dermal contact through soil for adults in both areas were higher than the cancer risk of dermal contact through paddy water. The potential cancer risk of dermal contact through soil for adults in both areas were lower than the potential cancer risk of ingestion through soil in both areas.

In generally, the minimum, average, $95^{\text {th }}$ percentile, and maximum of the potential cancer risk of dermal contact through soil and water for adults; the minimum, average, $95^{\text {th }}$ percentile and maximum of the potential cancer risk of ingestion through soil for adults; the potential total cancer risk through soil and paddy water in both areas were less than $1 * 10-6$, being within the acceptable level.

\subsubsection{Potential Non-cancer Risk from Lifetime Exposure Dose and Acute Exposure Dose}

The distribution of the potential non-cancer risk from both lifetime and acute exposure dose are presented in Fig. 4 and Table S9, and Fig 5 and Table S10.

The results indicate that the minimum, average, $95^{\text {th }}$ percentile and maximum of the potential non-cancer risk from both of lifetime and acute dermal contact exposure dose through soils; the minimum, average, $95^{\text {th }}$ percentile and maximum of the potential non-cancer risk from 
both lifetime and acute dermal contact exposure dose through paddy water; the minimum, average, $95^{\text {th }}$ percentile and maximum of the potential non-cancer risk from the both lifetime and acute ingestion exposure dose through soil for adult in two study areas were below 1 . The minimum, average, $95^{\text {th }}$ percentile and maximum of the potential non-cancer risk from both lifetime and acute dermal contact exposure dose through soils; the minimum, average, $95^{\text {th }}$ percentile and maximum of the potential non-cancer risk from the lifetime and acute dermal contact exposure dose through paddy water; the minimum, average, $95^{\text {th }}$ percentile and maximum of the potential non-cancer risk from both lifetime and acute ingestion exposure dose through soil for adults of these two areas below 1 . The potential total non-cancer risk from both lifetime exposure dose and acute exposure dose through paddy water and soil in these two areas were less than 1. Based on the US EPA (2010) report, if $\mathrm{HI}<1$, the exposed individual was unlikely to obviously experience adverse health effects. On the contrary, if $\mathrm{HI}>1$, there was a chance of non-carcinogenic effect. Thus, the potential non-cancer risk from Pymetrozine through both soil and paddy water were relatively low, indicating an acceptable risk level.

The results also indicated that the potential non-cancer risk from both lifetime and acute dermal contact dose through soil for adults in both areas were higher than potential non-cancer risk from both lifetime and acute dermal contact dose through paddy water separately. The potential non-cancer risk from both lifetime and acute dermal contact exposure dose through soil for adults in both areas were lower than the potential non-cancer risk from both lifetime and acute ingestion exposure dose through soil in both areas and these results are consistent with the previous results (Bhandari et al., 2020, Landrigan and Goldman, 2011, Pan et al., 2018, Yadav et al., 2016).

\subsection{Sensitivity Analysis}


452 The percentage contribution of exposure pathways is used to determine which variables and 453 pathways most strongly influence the potential risk estimate (Tudi et al., 2019). Percentage contribution of exposure pathways to potential total risk is calculated by the following equation:

455

456

$$
\text { HItotal }=\sum_{i=1}^{n}(H I i)
$$

The result indicated that in both areas, the risk index from ingestion exposure dose from Pymetrozine through soil took up the highest percentage in the potential total cancer risk $(98.46 \%)$ and the potential total non-cancer risk $(98.28 \%)$, followed by the potential risk index of dermal contact exposure dose from Pymetrozine through soil and then the potential risk index of dermal contact exposure dose from Pymetrozine through paddy water (Table 1)

\section{$465 \quad 4.5$ Uncertainty Analysis}

466 The following uncertainties limit the validity of the results of this research work. (1) the concentrations of pesticides across the different rice growing seasons are different (Zhu et al., 2017), but seasonal variation of pesticides were not investigated. Thus, the exposure and potential risk level of Pymetrozine may not present the real situation in this study. (2) CSF and RFD were treated as constants for all members of population, but they should be different from person to person (Phung et al., 2012a, Phung et al., 2013). In this study, each input parameter is considered by a point estimate. Variability and uncertainty should be considered when 473 choosing the input (Sadler et al., 2016). The traditional way of managing uncertainty and 474 variability has been to incorporate safety factors or use conservative assumptions, which can 
lead to unrealistically high estimations which are neither transparent nor efficient when further testing or measures might be necessary (Atabila, 2017). Conversely, it is also possible to underestimate the exposure for sensitive populations. Deterministic estimations cannot explain the number of individuals that might be exposed to a dose over a reference value or the probability of a certain exposure (Atabila et al., 2018a). Furthermore, deterministic estimations are given with a precision that does not reflect the uncertainty and variability that is inevitable in such assessments. However, variability and uncertainty are not considered or evaluated in the calculations of this study. (3) The exposure factors for the body weight and life time frequency as constants for all members of population, but they could vary from person to person; the data analyses showed that there is a major inter individual variability inherent in these exposure factors, which must be considered in risk assessments (Tudi et al., 2019). However, there is not only variability between individuals within the same gender and age group, but also between different age groups and between females and males (Filipsson, 2011). However, this study does not consider this aspect. (4) the concentrations of parent material of Pymetrozine found in the water and soil samples were considered as a main hazardous source and residents were mainly exposed to it but the metabolism products of the Pymetrozine in both soil and paddy water could also pose risk to human (US EPA, 2010). However, the potential risk of the metabolism products of Pymetrozine from soil and paddy water was not considered in this study, thus it somewhat underestimated the level of both cancer and non-cancer risk assessment.

\section{Conclusions}

The potential acute dermal exposure levels of Pymetrozine through soil and paddy water, acute ingestion exposure level of Pymetrozine through soil, total acute dermal exposure levels of Pymetrozine through soil, total acute dermal exposure levels of Pymetrozine through paddy water, and potential total acute ingestion exposure levels of Pymetrozine through soil peaked 
500

501

502

503

504

505

506

507

508

509

510

511

512

513

514

515

516

517

518

519

520

521

522

523

at the day of insecticide application and returned to the normal range approximately 21-days after insecticide application.

The potential total dermal exposure and ingestions exposure levels of Pymetrozine through soil and paddy water were slightly different from the potential acute dermal exposure levels on the day of insecticide spraying due to the small contribution after 1, 3, 5, 7, 9, 14 and 21-day exposure levels to the ADDT.

For both areas, the main exposure routes for potential carcinogenic and potential noncarcinogenic risks of Pymetrozine were the soil ingestion, followed by the soil dermal contact and then the paddy water dermal contact. Thus, the soil ingestion route caused the highest exposure of the potential carcinogenic risk and non-carcinogenic risk to human health.

In general, the results of potential risk characterization indicate that agriculture communities have a relatively low potential risk of adverse health effects from the Pymetrozine application in rice growing areas.

Authors' contributions MT: conceptualization, data curation, formal analysis, methodology, validation, writing - original draft, and writing — review and editing. RDH: validation, resources, supervision, funding acquisition, and writing — review and editing. ST: validation, resources, supervision. LW: validation, resources, supervision. AA: validation, resources, supervision: RS: validation, resources, supervision; DC: validation, resources, supervision; DTP: validation, resources, and project administration'

Funding: This study is funded by the Griffith University. 
525 Data availability: The datasets used and/or analysed during the current study are available

526 from the corresponding author on reasonable request.

\section{Compliance with ethical standards}

\section{Conflict of interest}

529 The authors declare that they have no conflict of interest, financial or other. This article does 530 not contain any studies involving human participants or animals.

\section{Ethical approval.}

532 Consent to participate.

533 Consent to publish

534

535

536

537

538

539

540

541

542

543

544 Yuan, and Mr Feng Yang from the Beijing ECO-SAF Technology Co., Ltd, and Mr Min Luo

545 from the Shuang Feng Agriculture Department Lou Di city Hunan Province China who

546 provided technical support during my fieldwork. Furthermore, I express my thankfulness to all 
sincere thanks to all the Chinese students graduated from CEPH who support and encourage

me during the fieldwork.

\section{References}

AKTAR, W., SENGUPTA, D. \& CHOWDHURY, A. 2009. Impact of pesticides use in agriculture: their benefits and hazards. Interdisciplinary toxicology, 2, 1-12.

ATABILA, A. 2017. Health Risk Assessment and Management of Chlorpyrifos Exposure among Rice Farmers in Ghana. Griffith University Queensland, Australia.

ATABILA, A., PHUNG, D. T., HOGARH, J. N., SADLER, R., CONNELL, D. \& CHU, C. 2018a. Health risk assessment of dermal exposure to chlorpyrifos among applicators on rice farms in Ghana. Chemosphere, 203, 83-89.

ATABILA, A., SADLER, R., PHUNG, D. T., HOGARH, J. N., CARSWELL, S., TURNER, S., PATEL, R., CONNELL, D. \& CHU, C. 2018b. Biomonitoring of chlorpyrifos exposure and health risk assessment among applicators on rice farms in Ghana. Environmental Science and Pollution Research, 25, 20854-20867.

BHANDARI, G., ATREYA, K., SCHEEPERS, P. T. \& GEISSEN, V. 2020. Concentration and distribution of pesticide residues in soil: Non-dietary human health risk assessment. Chemosphere, 253, 126594.

DAMALAS, C. A. \& ELEFTHEROHORINOS, I. G. 2011. Pesticide exposure, safety issues, and risk assessment indicators. International journal of environmental research and public health, 8, 1402-1419.

DEBLEECKER, J. L. 1995. The intermediate syndrome in organophosphate poisoning: an overview of experimental and clinical observations. Journal of Toxicology: Clinical Toxicology, 33, 683686.

DELCOUR, I., SPANOGHE, P. \& UYTTENDAELE, M. 2015. Literature review: Impact of climate change on pesticide use. Food Research International, 68, 7-15.

FILIPSSON, M. 2011. Uncertainty, variability and environmental risk analysis. Linnaeus University Press.

GONG, J., ZHENG, K. M., YANG, G. Q., ZHAO, S., ZHANG, K. K. \& HU, D. Y. 2019. Determination, residue analysis, risk assessment and processing factor of pymetrozine and its metabolites in Chinese kale under field conditions. Food Additives and Contaminants Part a-Chemistry Analysis Control Exposure \& Risk Assessment, 36, 141-151.

JIA, G. F., ZENG, L. R., ZHAO, S., GE, S. J., LONG, X. F., ZHANG, Y. P. \& HU, D. Y. 2019. Monitoring residue levels and dietary risk assessment of pymetrozine for Chinese consumption of cauliflower. Biomedical Chromatography, 33.

KOVACOVA, J., HRBEK, V., KLOUTVOROVA, J., KOCOUREK, V., DRABOVA, L. \& HAJSLOVA, J. 2013. Assessment of pesticide residues in strawberries grown under various treatment regimes. Food Additives and Contaminants Part a-Chemistry Analysis Control Exposure \& Risk Assessment, 30, 2123-2135.

LANDRIGAN, P. J. \& GOLDMAN, L. R. 2011. Children's vulnerability to toxic chemicals: a challenge and opportunity to strengthen health and environmental policy. Health Affairs, 30, 842-850.

LI, C., YANG, T., HUANGFU, W. \& WU, Y. 2011. Residues and dynamics of pymetrozine in rice field ecosystem. Chemosphere, 82, 901-904.

PAN, L., SUN, J., LI, Z., ZHAN, Y., XU, S. \& ZHU, L. 2018. Organophosphate pesticide in agricultural soils from the Yangtze River Delta of China: concentration, distribution, and risk assessment. Environmental Science and Pollution Research, 25, 4-11.

PEREIRA, L. C., DE SOUZA, A. O., BERNARDES, M. F. F., PAZIN, M., TASSO, M. J., PEREIRA, P. H. \& DORTA, D. J. 2015. A perspective on the potential risks of emerging contaminants to human and environmental health. Environmental Science and Pollution Research, 22, 13800-13823. 
PHUNG, D. T., CONNELL, D., MILLER, G. \& CHU, C. 2012a. Probabilistic assessment of chlorpyrifos exposure to rice farmers in Viet Nam. Journal of exposure science \& environmental epidemiology, 22, 417-423.

PHUNG, D. T., CONNELL, D., MILLER, G., RUTHERFORD, S. \& CHU, C. 2012b. Pesticide regulations and farm worker safety: the need to improve pesticide regulations in Viet Nam. Bulletin of the World Health Organization, 90, 468-473.

PHUNG, D. T., CONNELL, D., MILLER, G., RUTHERFORD, S. \& CHU, C. 2012c. Pesticide regulations and farm worker safety: the need to improve pesticide regulations in Viet Nam. Bulletin of the World Health Organization, 90, 468-473.

PHUNG, D. T., CONNELL, D., YU, Q. \& CHU, C. 2013. Health Risk Characterization of Chlorpyrifos Using Epidemiological Dose - Response Data and Probabilistic Techniques: A Case Study with Rice Farmers in Vietnam. Risk analysis, 33, 1596-1607.

SADLER, R., MAETAM, B., EDOKPOLO, B., CONNELL, D., YU, J., STEWART, D., PARK, M.-J., GRAY, D. \& LAKSONO, B. 2016. Health risk assessment for exposure to nitrate in drinking water from village wells in Semarang, Indonesia. Environmental pollution, 216, 738-745.

SCHREINEMACHERS, P., CHEN, H.-P., NGUYEN, T. T. L., BUNTONG, B., BOUAPAO, L., GAUTAM, S., LE, N. T., PINN, T., VILAYSONE, P. \& SRINIVASAN, R. 2017. Too much to handle? Pesticide dependence of smallholder vegetable farmers in Southeast Asia. Science of the Total Environment, 593, 470-477.

SHUQIN, J. \& FANG, Z. 2018. Zero growth of chemical fertilizer and pesticide use: China's objectives, progress and challenges. Journal of resources and ecology, 9, 50-58.

SUGENG, A. J., BEAMER, P. I., LUTZ, E. A. \& ROSALES, C. B. 2013. Hazard-ranking of agricultural pesticides for chronic health effects in Yuma County, Arizona. Science of the total environment, 463, 35-41.

TUDI, M., DANIEL RUAN, H., WANG, L., LYU, J., SADLER, R., CONNELL, D., CHU, C. \& PHUNG, D. T. 2021. Agriculture Development, Pesticide Application and Its Impact on the Environment. International Journal of Environmental Research and Public Health, 18, 1112.

TUDI, M., PHUNG, D. T., RUAN, H. D., YANG, L.-S., GUO, H.-J., CONNELL, D., SADLER, R. \& CHU, C. 2019. Difference of trace element exposed routes and their health risks between agriculture and pastoral areas in Bay County Xinjiang, China. Environmental Science and Pollution Research, 26, 14073-14086.

URAM, C. 1989. International regulation of the sale and use of pesticides. Nw. J. Int'I L. \& Bus., 10, 460.

WANG, J., CHU, M. \& MA, Y. 2018. Measuring rice farmer's pesticide overuse practice and the determinants: A statistical analysis based on data collected in Jiangsu and Anhui Provinces of China. Sustainability, 10, 677.

WESSELING, C., MCCONNELL, R., PARTANEN, T. \& HOGSTEDT, C. 1997. Agricultural pesticide use in developing countries: health effects and research needs. International journal of health services, 27, 273-308.

WONG, H. L., GARTHWAITE, D. G., RAMWELL, C. T. \& BROWN, C. D. 2018. Assessment of exposure of professional agricultural operators to pesticides. Science of the Total Environment, 619, 874882.

YADAV, I. C., DEVI, N. L., LI, J., ZHANG, G. \& SHAKYA, P. R. 2016. Occurrence, profile and spatial distribution of organochlorines pesticides in soil of Nepal: Implication for source apportionment and health risk assessment. Science of the Total Environment, 573, 15981606.

YADAV, I. C., DEVI, N. L., SYED, J. H., CHENG, Z., LI, J., ZHANG, G. \& JONES, K. C. 2015. Current status of persistent organic pesticides residues in air, water, and soil, and their possible effect on neighboring countries: A comprehensive review of India. Science of the Total Environment, 511, 123-137. 
YANG, C.-C. \& DENG, J.-F. 2007. Intermediate syndrome following organophosphate insecticide poisoning. Journal of the Chinese Medical Association, 70, 467-472.

YU, H., SUN, H., WANG, X., LIANG, Y., GUO, M., YU, J., YANG, M., ZHANG, X., LUO, F. \& ZHOU, L. 2020. Residue behavior and safety evaluation of pymetrozine in tea. Journal of the Science of Food and Agriculture.

ZHANG, W., JIANG, F. \& OU, J. 2011. Global pesticide consumption and pollution: with China as a focus. Proceedings of the International Academy of Ecology and Environmental Sciences, 1, 125.

ZHANG, Y., ZHANG, L., XU, P., LI, J. \& WANG, H. 2015. Dissipation and residue of pymetrozine in rice field ecosystem. Environmental monitoring and assessment, 187, 78.

ZHU, S., NIU, L., AAMIR, M., ZHOU, Y., XU, C. \& LIU, W. 2017. Spatial and seasonal variations in airsoil exchange, enantiomeric signatures and associated health risks of hexachlorocyclohexanes ( $\mathrm{HCHs}$ ) in a megacity Hangzhou in the Yangtze River Delta region, China. Science of the Total Environment, 599, 264-272. 
Figures
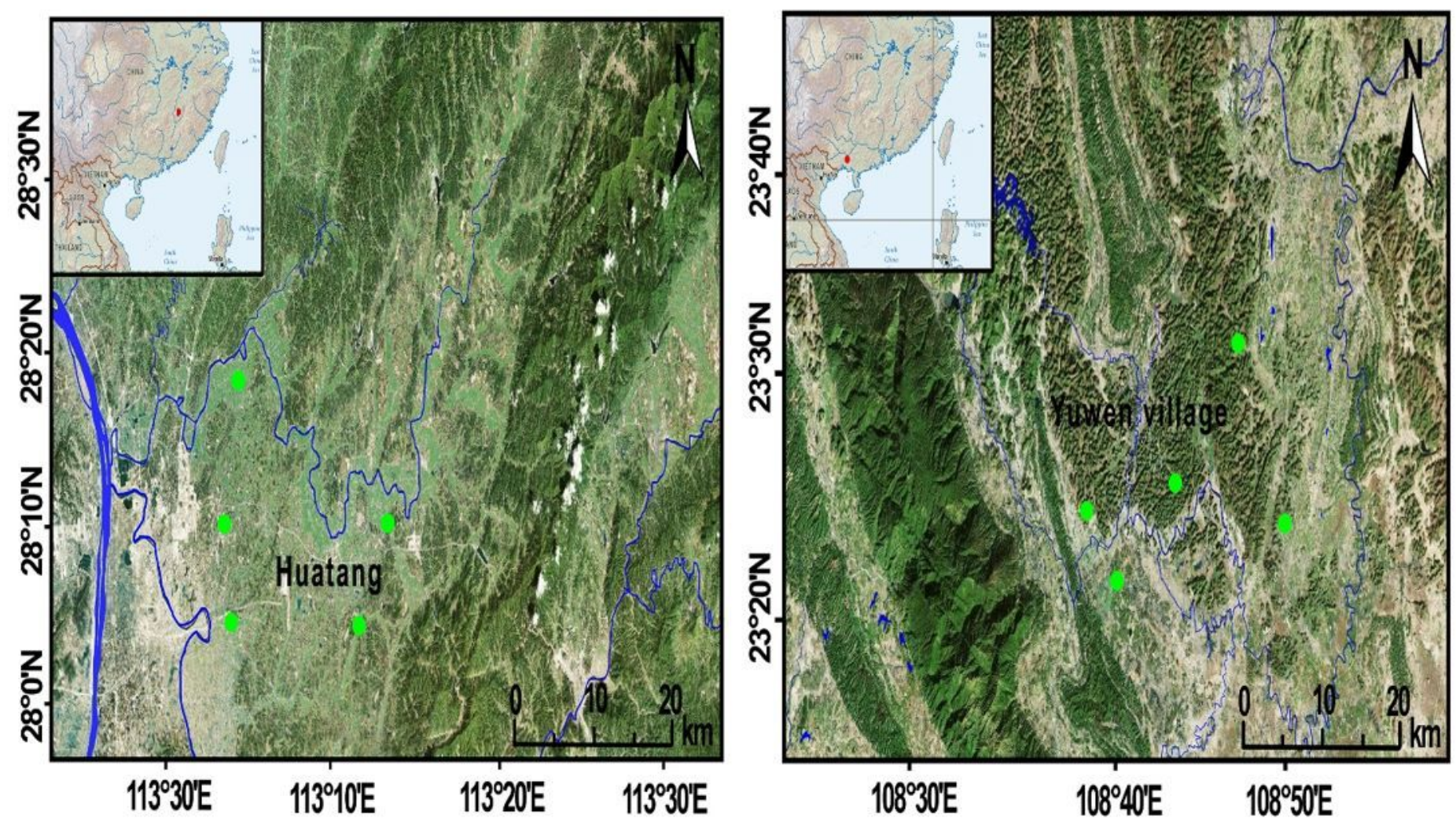

Figure 1

Location Map of the Sampling Sites 

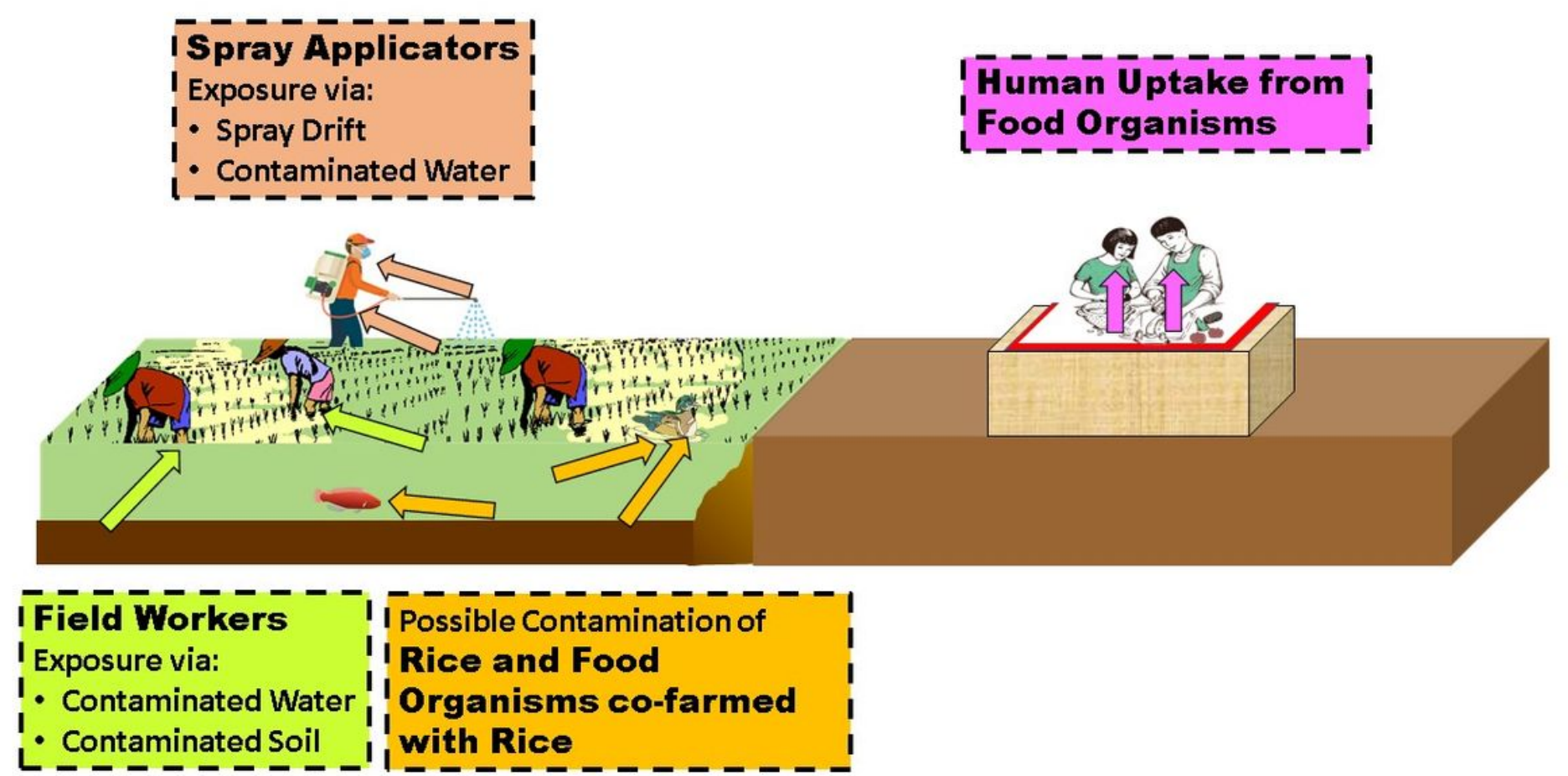

Figure 2

Conceptual Diagram of the Exposure Routes
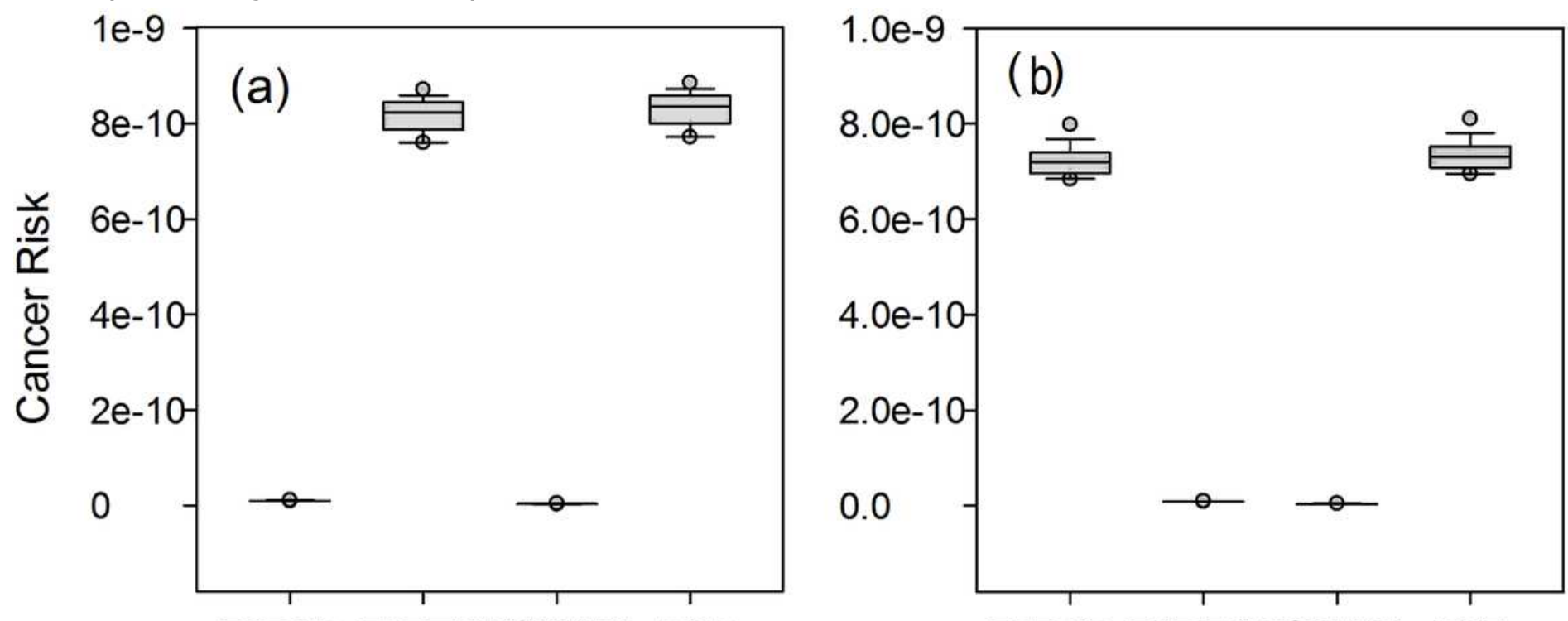

TCRSD TCRTSI TCRWDI TCR

Figure 3

Cancer Risk through Soil and Paddy Water in Guangxi and Hunan Note: a:Hunan (adult); b:):Guangxi (adult); TCRSD: cancer risk of the dermal contact through soil ; TCRTSI: cancer risk of the ingestion 
through soil; TCRWD: cancer risk of the dermal contact through soil; TCR: sum of the cancer risk through soil and water through dermal and ingestion
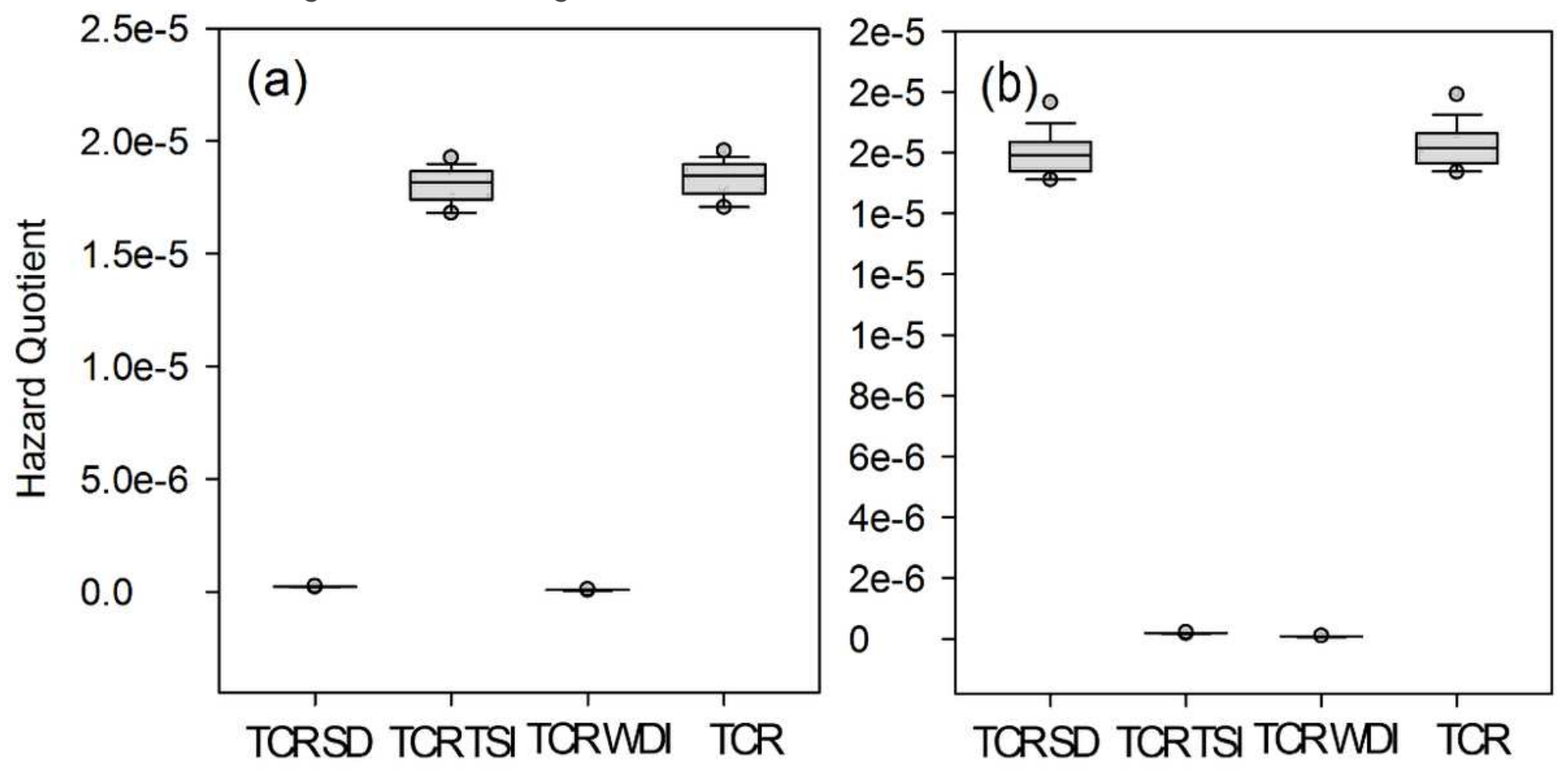

Figure 4

Non-Carcinogenic Risk for Lifetime Dose through Soil and Paddy Water in Guangxi and Hunan Note: a:Hunan (adult); b:):Guangxi (adult); TCRSD: non-cancer risk of the dermal contact through soil ; TCRTSI: non-cancer risk of the ingestion through soil; TCRWD: non-cancer risk of the dermal contact through soil; TCR: sum of the non-cancer risk through soil and water through dermal and ingestion
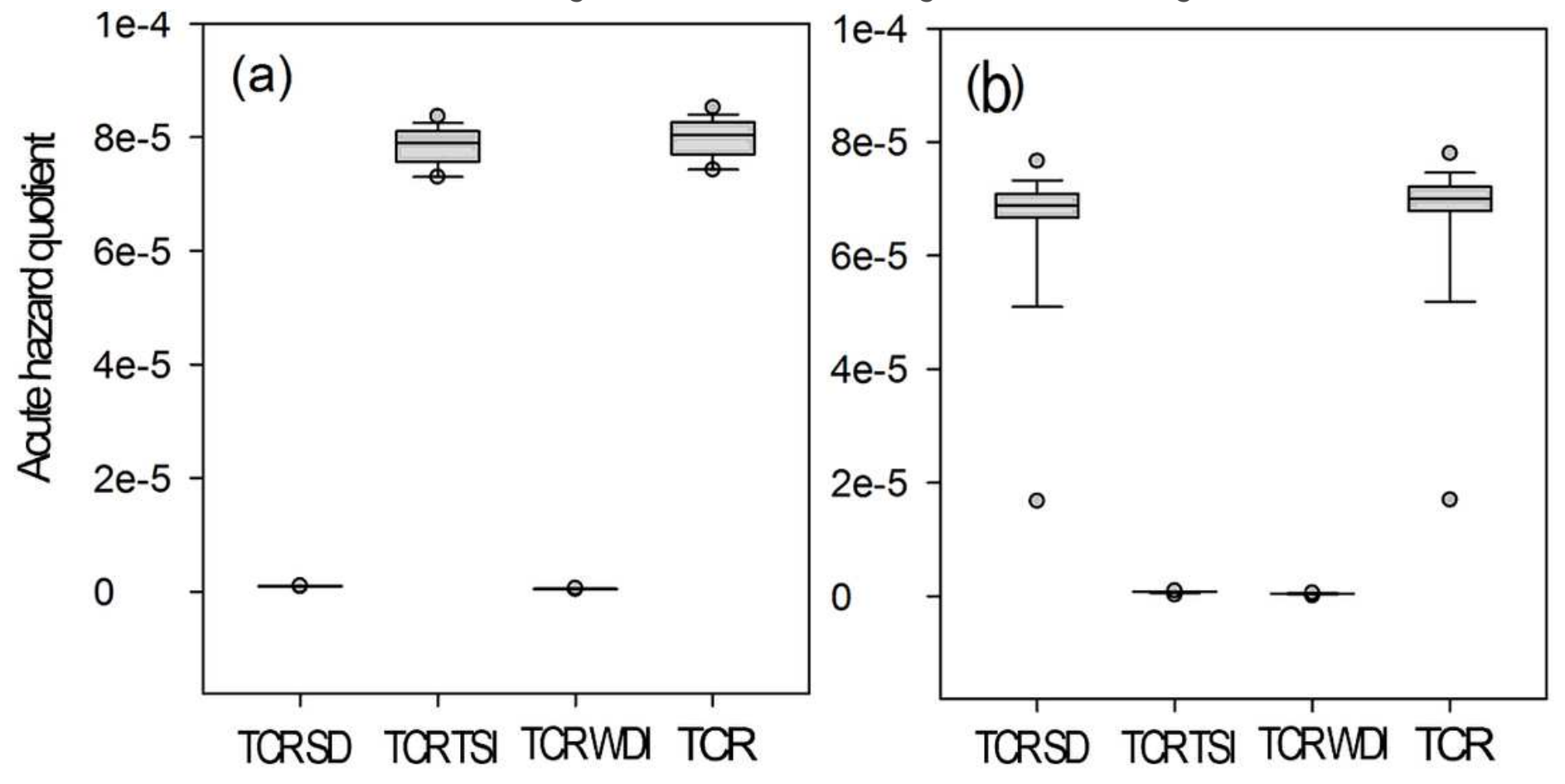


\section{Figure 5}

Non-Carcinogenic Risk Quotient from Acute Dose through Soil and Paddy Water in Guangxi and Hunan Note: a:Hunan (adult); b:):Guangxi (adult); TCRSD: non-cancer risk of the dermal contact through soil ; TCRTSI: non-cancer risk of the ingestion through soil; TCRWD: non-cancer risk of the dermal contact through soil; TCR: sum of the non-cancer risk through soil and water through dermal and ingestion

\section{Supplementary Files}

This is a list of supplementary files associated with this preprint. Click to download.

- SupplementMelanie25052021.docx 